\title{
The effects of larval diet on adult life-history traits of the black soldier fly, Hermetia illucens (Diptera: Stratiomyidae)
}

\author{
Paola GOBBI, Anabel MARTÍNEZ-SÁNCHEZ and SANTos ROJO
}

\begin{abstract}
Departamento de Ciencias Ambientales y Recursos Naturales / Instituto Universitario CIBIO, Facultad de Ciencias, Universidad de Alicante, Apdo.99, E-03080 Alicante, Spain; e-mails: paogobbi@hotmail.com; anabel.martinez@ua.es; santos.rojo@ua.es
\end{abstract}

Key words. Diptera, Stratiomyidae, Hermetia illucens, larval diet, wing morphometry, immature stages, ovarian development, hen feed, meat meal

\begin{abstract}
Larvae of Hermetia illucens feed on different types of decomposing organic matter and their development depends on the quality and quantity of food ingested. In this study the effect of three artificial diets was analyzed, namely hen feed, meat meal and a mixture of these two diets. The effects of diet on ovarian development, size, mortality, duration of the larval and pupal stages and sex ratio were studied. Results indicate that the meat meal diet was the worst of the three diets in terms of percentage mortality and duration of the larval and pupal stages. We conclude that food ingested by the black soldier fly larvae determines both the physiological and morphological development of the adults.
\end{abstract}

\section{INTRODUCTION}

Use of larvae of the black soldier fly, Hermetia illucens (L., 1758), (Diptera: Stratiomyidae) to treat organic wastes or livestock manure is proposed as a promising and effective technology (Sheppard \& Newton, 2000; Newton et al., 2005a; Myers et al., 2008; Diener et al., 2009). This species is highly versatile and can feed on a wide variety of organic matter, from vegetable residues to decaying animal tissues (Lardé, 1989; St-Hilaire et al., 2007; Hem et al., 2008; Martínez-Sánchez et al., 2011). The black soldier fly (BSF) is able to reduce the volume of organic matter by $42-56 \%$ by consuming and accumulating it as protein ( $40 \%$ or more) in its body (Newton et al., 2005b). Some of the abiotic factors required by the BSF are known, such as the range of temperatures and relative humidity it requires for development (Booth \& Sheppard, 1984; Sheppard et al., 2002) and the influence of light on adult behaviour (Zhang et al., 2010; Gobbi et al., 2013).

Although the economic importance of the BSF is well established, some important aspects of the life cycle of $H$. illucens are unknown. It is well known that the quality of larval food affects the growth, survival and biological traits of adult flies (e.g. Roper et al., 1996; Blackmore \& Lord, 2000). Under optimal conditions, BSF larvae take two weeks to reach the prepupal stage, but this period can increase to four months if food is limited (Furman et al., 1959; Myers et al., 2008). The life-history traits of adults varies (Liu et al., 2008), depending on the quantity and quality of the food supplied to them as larvae, as the adults do not feed (Tomberlin et al., 2002)

Geometric analysis of the size of the wings is a widely used method for studying the effect of the quality of larval food on the growth of Diptera (Jirakanjanakit et al., 2007; Soto et al., 2008; Morales-Vargas et al., 2010). Morphometric analysis of wing landmarks has been used to determine the variability in size of laboratory strains of flies and differences between natural populations (e.g. Milankov et al., 2010; Prudhomme et al., 2012). Measurements of differences in wing size (based on centroid size analysis) provide information that can be evaluated statistically and critically (Rohlf, 1993). On the other hand, the development of the ovaries and number of ovarioles in insects is genetically determined in most species. Nevertheless, the number of ovarioles and their size can also vary depending on the quantity and quality of food consumed and stored during their life cycle (Magnarelli et al., 1982; Engelman, 1984).

The main aim of this study was to determine how the quality of larval diet affects preimaginal development and female fecundity in $H$. illucens. It is likely that larval diet affects mass reared flies, as larger females have larger ovaries and lay more eggs than small females. In this study we tested this hypothesis and determined the biological parameters of BSF by focusing on the following specific objectives: how does the quality of the larval diet affect (a) their survival, (b) size of adults, (c) duration of development of larval and pupal stages and (d) the size of the ovaries and stage of development of oocytes.

\section{MATERIAL AND METHODS}

This study was carried out at the University of Alicante (Alicante province, SE Spain). A colony of black soldier fly was established in 2008 from commercially available pupae (Insect Science Resource Company, Tifton, GA, USA). Adult flies that emerged from the pupae were placed in $3 \mathrm{~m}^{3}$ cages and kept under controlled conditions in a greenhouse $\left(25 \pm 5^{\circ} \mathrm{C}, 50 \pm\right.$ $10 \% \mathrm{RH}$ and natural light). Adults were provided with water and sugar ad libitum and approximately 7 days after emergence, a mixture of water and hen feed $(500 \mathrm{~g}$ diluted in $800 \mathrm{ml}$ of water) was provided for them to lay their eggs on. This medium was placed in a small container $(8.5 \times 8.5 \mathrm{~cm})$ the surface of which was covered with strips of cardboard with holes along the edges, which provided the flies with sites for laying eggs. The 
containers were changed daily and the medium with the eggs transferred to a climatic chamber kept at $25^{\circ} \mathrm{C}, 60 \% \mathrm{RH}$ and a photoperiod of $12 \mathrm{~L}: 12 \mathrm{D}$, which are suitable for egg development. Later (after $72 \mathrm{~h}$ ), hen feed medium was supplied ad libitum to the developing larvae. When the larvae reached the prepupal stage, they left the rearing medium and pupated in sand in a tray placed underneath the container. The pupae were collected and transferred to the cages for adults kept in a greenhouse.

\section{Experimental design}

Three different diets were prepared for feeding larvae: hen feed $(\mathrm{H})$ [500 g diluted in $800 \mathrm{ml}$ of water], a mixture of hen feed and meat meal $(\mathrm{H}+\mathrm{M})[250 \mathrm{~g}$ hen feed $+250 \mathrm{~g}$ meat meal diluted in $800 \mathrm{ml}$ of water] and meat meal (M) [500 g diluted in $800 \mathrm{ml}$ of water]. Six hundred first instar larvae (younger than $24 \mathrm{~h}$; which were individually counted with the aid of entomological tweezers and a brush to avoid damaging the larvae) were placed on a diet, which was placed in a chamber kept at $25^{\circ} \mathrm{C}$, $60 \% \mathrm{RH}$ and a photoperiod of $12 \mathrm{~L}: 12 \mathrm{D}$. This was replicated five times for each diet. Once all the larvae pupated, as commented above, they were transferred to cages $(40 \times 40 \times 40 \mathrm{~cm})$ containing sugar and water ad libitum. The dates of pupation (first to pupate) and adult emergence (first to emerge), sex ratio and weight of remaining diet were recorded; morphometric data of 30 males and 30 females (chosen at random) were recorded and the percentage larval, pupal and adult mortality calculated.

Morphometric data recorded were the length of adults measured with a digital caliper $( \pm 0.01 \mathrm{~mm})$, after which their wings were removed and measured. The wings from each fly were glued to a transparent film, to which a note of the replicate and diet was added. Wing size was calculated as centroid size, after which wings were scanned and measured using tps software (Rohlf, 2009): tps file utility program (tpsUtil), with which tps files were created to minimize any bias; tps digitize landmarks \& outlines from image files, scanner or video (tpsDig), which allowed selection of morpho-geometrical points (landmarks) from the images to define the configuration of each wing and convert the points into two-dimensional coordinates; and finally, tps relative warps analysis (tpsRelw), the principal component of this program that processes the coordinate matrix by calculating the centroid size. In this study, the centroid size was calculated for all 21-landmark configurations for each wing, manually plotted at main vein intersections (Fig. 1). Centroid size, an isometric estimator of size, was calculated from the square root of the sum of the squared distances between the centre of the object (i.e. wing centroid) and its landmarks (Bookstein, 1991; Zelditch et al., 2004). Differences in wing size were analyzed by comparing females and males separately. In most cases the right wing was measured, but when this was impossible the left wing was used.

To determine the effect of larval diet on the development of the ovaries of females and size of individuals, females were collected on day 1 (the day on which $90 \%$ of adults emerged), 5 , 10,15 and 20. Ten females from each replicate were individually frozen for $72 \mathrm{~h}$. Then, their abdomens were opened and ovaries stained with toulidina blue and orange $\mathrm{G}(0.03 \mathrm{~g}$ in $6 \mathrm{ml}$ of distilled $\mathrm{H}_{2} \mathrm{O} ; 1 \mathrm{~min}$ ). Maximum width (MWO) and length (MLO) of the ovary and maximum width (MWob) and length (MLob) of the largest basal oocyte were measured using a micrometre (magnification 0.63 and 6 , respectively). The length of females was measured using a digital caliper $( \pm 0.01 \mathrm{~mm})$ and wings were removed and subjected to a morphometric analysis.

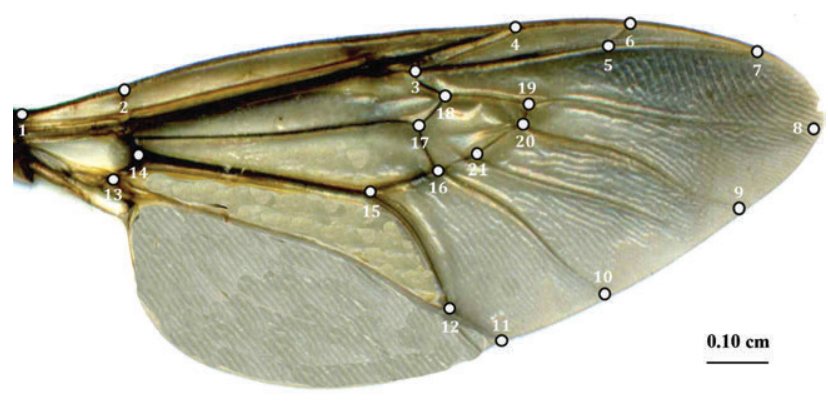

Fig. 1. A wing of Hermetia illucens with the 21 landmarks used in the morphometric analysis.

\section{Statistical analysis}

To determine possible differences in the size of the wings, mortality and duration of each of the stages in development the non-parametric Kruskal-Wallis $(H)$ (Dunn's test $(Q)$ was used to determine the difference in rank means) test and Mann-Whitney $(U)$ test were used. To establish possible relationships that may exist between wing size and the measurements MWO, MLO, MWob and MLob, Pearson correlation analysis was used, and the non-parametric Mann-Whitney $(U)$ test was used to determine possible differences between MWO, MLO, MWob and MLob of flies reared on different diets. The program used was SigmaStat (v3.5 for Windows) and values of $p$ greater than 0.05 were discarded.

\section{RESULTS}

\section{Mortality, duration of stages and sex-ratio}

Quantitative analysis of the remains of each type of diet demonstrated that larvae reared on meat meal ingested an average of $167.60 \pm 67.80 \mathrm{~g}$ (dry weight) of the diet, those reared on hen feed $354.80 \pm 27.78 \mathrm{~g}$ (dry weight), and the value was intermediate for larvae reared on the mixture, $290.60 \pm 34.79 \mathrm{~g}$ (dry weight). The highest percentage mortality in larval and pupal stages was recorded on the meat meal diet, for which the values were $60.00 \pm$ $3.00 \%$ and $80.00 \pm 3.00 \%$, respectively. In contrast, the percentage of mortality was very low on the hen feed diet, although it was higher in the larval $(7.00 \pm 3.00 \%)$ than the pupal stage $(1.00 \pm 0.60 \%)$. The percentage mortality on the hen feed and meat meal mixture was intermediate with no statistical differences in the two preimaginal stages (Fig. 2). In all cases the sex ratio was female biased but there were no significant differences between the three diets (Table 1).

The durations of the larval and pupal stages of flies fed on the three diets differed significantly (larva: $H=12.77$, $p<0.005$ and pupa: $H=12.23, p<0.005$ ) (Fig. 3). The larval period was similar on diets containing hen feed $(\mathrm{H}$ : $15.00 \pm 0.55$ days and $\mathrm{M}+\mathrm{H}: 19.00 \pm 1.00$ days $)$ and approximately 15 days shorter than on the meat meal diet (M: $33.00 \pm 1.09$ days). The duration of the pupal stage varied less than that of the larval stage. The duration was $16 \pm 0$ days on the hen feed and $16.00 \pm 0.45$ days on the hen feed + meat meal mixture, with the maximum of 19.00 \pm 0.55 days recorded for the meat meal diet. It was noted that on both hen feed diets $(\mathrm{H}$ and $\mathrm{M}+\mathrm{H})$, it took significantly less time to complete the life cycle than on the 


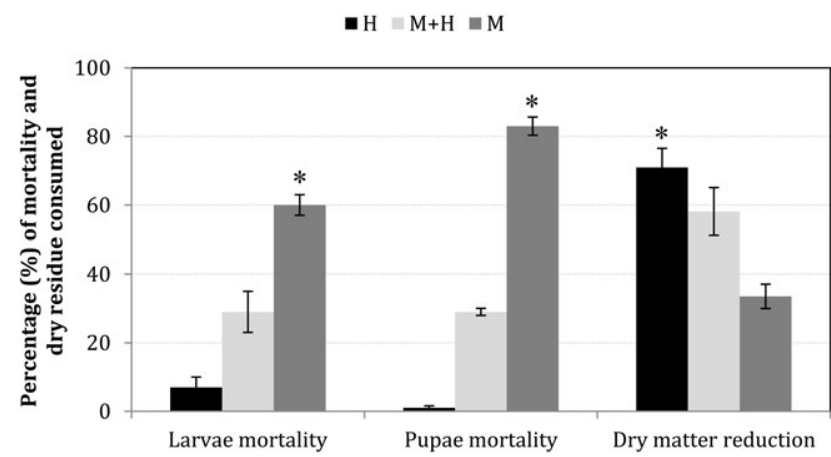

Fig. 2. Percentage larval and pupal mortality $( \pm \mathrm{SD})$ and total dry weight $( \pm \mathrm{SD})$ of Hermetia illucens reared on hen feed $(\mathrm{H})$, meat meal + hen feed $(\mathrm{M}+\mathrm{H})$ and meat meal $(\mathrm{M}) \operatorname{diets}\left({ }^{*} p<\right.$ 0.05 significant differences).

meat meal diet, on which they took almost twice as long $(H=12.68, p<0.005)$ (Fig. 3).

\section{Adult size}

Wing size was a good indicator of the body size of black soldier fly adults $(r=0.99 ; p=0.0001)$. Wing size of males and females differ and therefore the sizes of their wings were studied separately and differed significantly on the three diets $(H=479.78, p<0.001)$. In all cases, the wings of females were larger than those of males (Fig. 4). There were differences in the size of the wings of males $(H=233.40, p<0.001)$ and females $(H=$ $200.87, p<0.001)$ recorded in each of the treatments. For both males and females, the results showed significant differences between the sizes of the wings of the adults that developed on the hen feed and meat meal diets [(male, H: $Q=12.87, p<0.05$; M: $Q=14.24, p<0.05$ ) (female, $\mathrm{H}: Q=12.48, p<0.05$; $\mathrm{M}: Q=14.67, p<$ $0.05)]$, but not between these measurements and those recorded for adults reared on the hen feed + meat meal

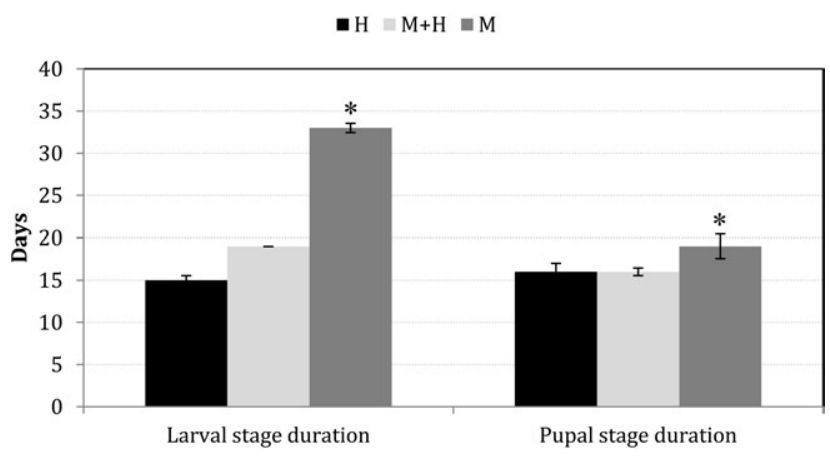

Fig. 3. Durations of the larval and pupal stages (median \pm SD) of Hermetia illucens reared on hen feed $(\mathrm{H})$, meat meal + hen feed $(\mathrm{M}+\mathrm{H})$ and meat meal $(\mathrm{M}) \operatorname{diets}\left({ }^{*} p<0.05\right.$ significant differences).

$\operatorname{diet}[($ male, $\mathrm{M}+\mathrm{H}: Q=1.51, p>0.05)$ (female, $\mathrm{M}+\mathrm{H}$ : $Q=2.39, p>0.05)$ ] (Fig. 4). In addition, the mixed diet was the best medium for rearing large adults, and those that were reared on the meat meal diet were smaller than those reared on the hen feed diets (see Table 1).

\section{Ovarian development}

Females reared on the mixed diet $(\mathrm{M}+\mathrm{H})$ had larger ovaries than those reared on the hen feed $(\mathrm{H})$ diet, on all of the days sampled (Table 2). On the first day, the oocytes of flies reared on the hen feed diet were larger than those on the mixed and meat meal diets. Females reared on meat meal had the smallest ovaries and basal oocytes, but this could only be measured on the first day (MLO 54.11 \pm 4.31; MWO 14.55 \pm 1.42 , MLob $14.43 \pm$ 0.39 , MWob $14.43 \pm 0.39$ ) due to the high mortality recorded on this diet (see Fig. 2). The maximum size of the ovary in terms of area was recorded from the fifth day for females reared on the hen feed and mixed diets (Fig.

TABLE 1. Average ( \pm SD) adult size (females and males) and sex ratio of flies the larvae of which were reared on the three diets (H: hen feed, $\mathrm{M}+\mathrm{H}$ : hen feed + meat meal and $\mathrm{M}$ : meat meal).

\begin{tabular}{|c|c|c|c|c|c|}
\hline \multirow{2}{*}{ Diets } & \multirow{2}{*}{ Replica } & \multirow{2}{*}{ Female length $(\mathrm{mm})$} & \multirow{2}{*}{ Male length (mm) } & \multicolumn{2}{|c|}{ Sex ratio } \\
\hline & & & & $\%$ Female & $\%$ Male \\
\hline \multirow{5}{*}{$\mathrm{H}$} & A & $15.66 \pm 1.20$ & $15.57 \pm 1.02$ & 62 & 38 \\
\hline & $\mathrm{B}$ & $16.22 \pm 1.16$ & $16.08 \pm 1.01$ & 55 & 45 \\
\hline & $\mathrm{C}$ & $15.95 \pm 1.32$ & $15.78 \pm 1.17$ & 58 & 42 \\
\hline & $\mathrm{D}$ & $15.89 \pm 1.29$ & $15.61 \pm 1.20$ & 56 & 44 \\
\hline & $\mathrm{E}$ & $15.77 \pm 1.05$ & $15.47 \pm 0.95$ & 56 & 44 \\
\hline \multirow{5}{*}{$\mathrm{M}+\mathrm{H}$} & A & $16.27 \pm 0.88$ & $15.89 \pm 1.03$ & 55 & 45 \\
\hline & $\mathrm{B}$ & $16.83 \pm 0.75$ & $15.64 \pm 1.19$ & 55 & 45 \\
\hline & $\mathrm{C}$ & $16.10 \pm 1.31$ & $16.02 \pm 1.08$ & 60 & 40 \\
\hline & $\mathrm{D}$ & $16.08 \pm 0.90$ & $15.97 \pm 1.11$ & 58 & 42 \\
\hline & $\mathrm{E}$ & $16.46 \pm 1.20$ & $16.01 \pm 1.08$ & 54 & 46 \\
\hline \multirow{5}{*}{ M } & $\mathrm{A}$ & $9.45 \pm 0.63$ & $8.06 \pm 0.87$ & 58 & 42 \\
\hline & $\mathrm{B}$ & $9.26 \pm 0.74$ & $8.34 \pm 0.86$ & 54 & 46 \\
\hline & $\mathrm{C}$ & $9.19 \pm 0.77$ & $8.51 \pm 0.86$ & 53 & 47 \\
\hline & $\mathrm{D}$ & $9.79 \pm 1.96$ & $8.32 \pm 0.92$ & 63 & 38 \\
\hline & $\mathrm{E}$ & $9.38 \pm 0.69$ & $8.24 \pm 0.86$ & 58 & 42 \\
\hline
\end{tabular}




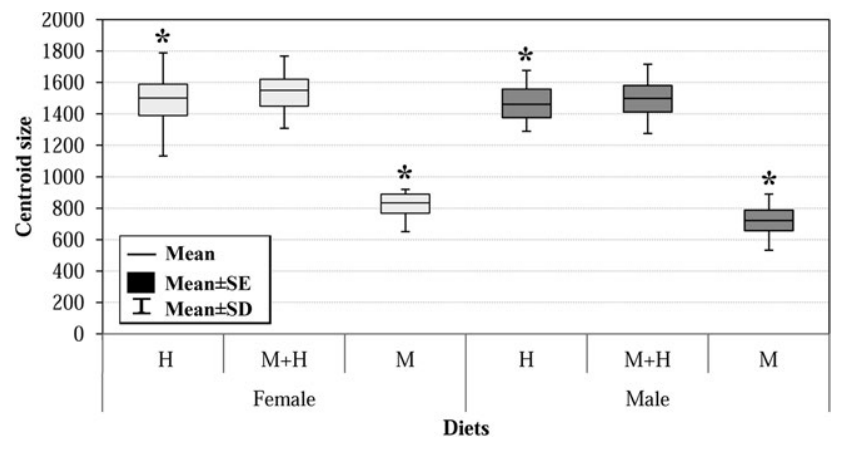

Fig. 4. Box plot of the mean, standard error and standard deviation of centroid sizes of the wings of female and male Hermetia illucens reared on the three diets $\left({ }^{*} p<0.05\right.$ significant differences).

$5 \mathrm{~A}$ ), and the maximum size of basal oocytes remained stable from the fifteenth day onwards (Fig. 5).

Females reared on the mixed diet were usually large, but when females of similar size reared on the different diets were compared, those that were reared on the hen feed + meat meal diet had similar sized or larger basal oocytes (day 10) than those reared on the hen feed diet (Fig. 6). The Pearson correlation analysis revealed positive relationships between adult size, wing size and ovary and basal oocyte size for all the treatments (Table 3; Fig. 6 ). The highest coefficient recorded was that for the relation between wing size and length but there was no correlation between the width of the ovary and size of the basal oocytes.

\section{DISCUSSION}

The larvae of the black soldier fly feeding on a wide variety of organic substrates derived from plants and animals reduce and transform these waste organic materials (Diener et al., 2009). This species mainly feeds during its larval stage and accumulates a sufficiently large store of fat to reduce or eliminate the need for the adult to feed (Sheppard et al., 2002). For this reason, the quality of food available plays a key role in the subsequent development of the adult. It is known that the larvae of insects tend to consume a balanced diet (i.e. optimum for its growth and development), which results in reproductively

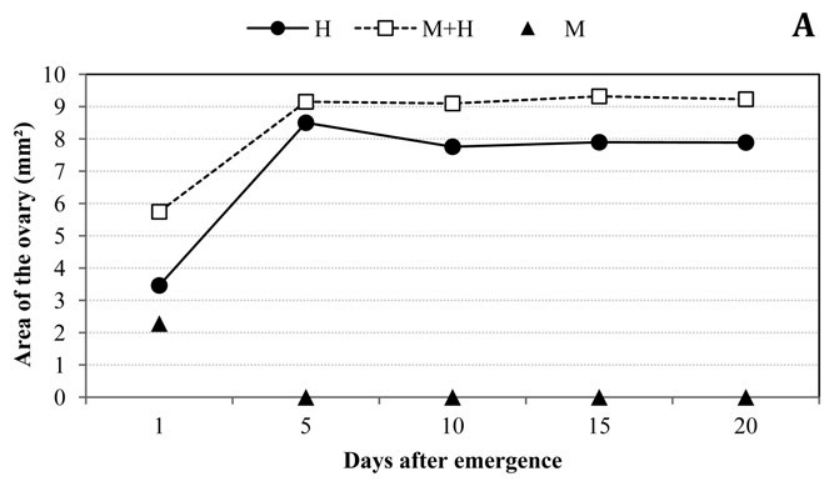

A

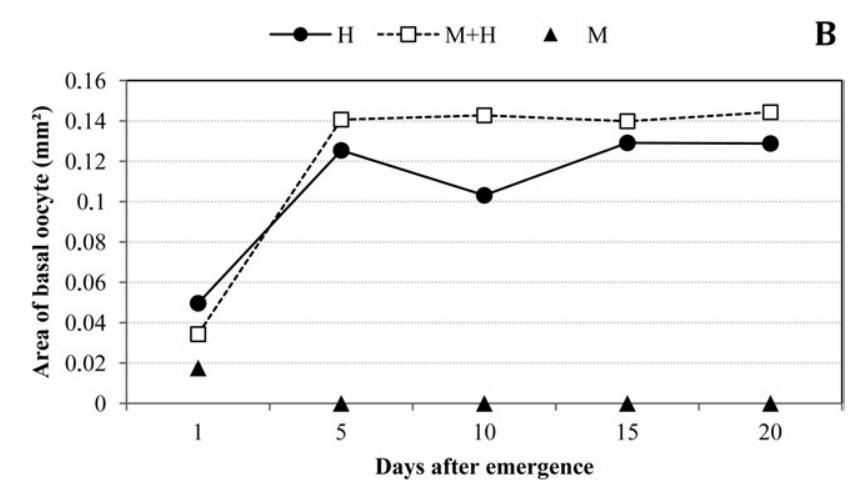

Fig. 5A-B: The area of the ovary and basal oocyte of females of Hermetia illucens reared on three diets $(\mathrm{H}$ : hen feed, $\mathrm{M}+\mathrm{H}$ : meat meal + hen feed and M: meat meal).

competitive adults (Parra, 1990). In this study, larvae reared on meat meal took longer to complete their development when compared with those reared on a hen feed diet or a mixture of both components. This result could be related to the physical texture of the medium based on meat meal (too thick) reducing larval food intake. In fact, the texture of the mixed medium was significantly different despite $50 \%$ of it being made up of meat meal. Other physical parameters, such as the quick drying out of this medium, could have negatively affected larval development by increasing mortality. These results agree with those for other fly species for which there are massrearing protocols, such as Musca domestica, which shows different rates of larval development and percentage sur-

TABLE 2. Size of the ovaries (length MLO and width MWO) and basal oocytes (length MLob and width MWob) (mean \pm SD) of adult Hermetia illucens the larvae of which were reared on hen feed $(\mathrm{H})$ and meat meal + hen feed $(\mathrm{M}+\mathrm{H})\left({ }^{*} p<0.05\right)[\mathrm{ovaries}$ of the females reared on meat meal were only measured on day 1 (see text)].

\begin{tabular}{|c|c|c|c|c|c|c|c|c|c|c|}
\hline $\begin{array}{c}\text { Day } \\
\text { measured }\end{array}$ & & 1 & 5 & 5 & 1 & 0 & & 5 & & 20 \\
\hline Diets & $\mathrm{H}$ & $\mathrm{M}+\mathrm{H}$ & $\mathrm{H}$ & $\mathrm{M}+\mathrm{H}$ & $\mathrm{H}$ & $\mathrm{M}+\mathrm{H}$ & $\mathrm{H}$ & $\mathrm{M}+\mathrm{H}$ & $\mathrm{H}$ & $\mathrm{M}+\mathrm{H}$ \\
\hline $\begin{array}{l}\text { MLO } \\
(\mathrm{mm})\end{array}$ & $4.41 \pm 0.53 *$ & $5.54 \pm 0.38^{*}$ & $6.63 \pm 0.51^{*}$ & $7.02 \pm 0.39^{*}$ & $6.51 \pm 0.48^{*}$ & $6.98 \pm 0.38^{*}$ & $6.51 \pm 0.41 *$ & $7.01 \pm 0.32 *$ & $6.54 \pm 0.48^{*}$ & $7.01 \pm 0.35^{*}$ \\
\hline $\begin{array}{l}\text { MWO } \\
(\mathrm{mm})\end{array}$ & $1 \pm 0.24^{*}$ & $1.32 \pm 0.32 *$ & $1.63 \pm 0.13$ & $1.66 \pm 0.14$ & $1.52 \pm 0.16^{*}$ & $1.66 \pm 0.14 *$ & $1.54 \pm 0.15^{*}$ & $1.70 \pm 0.12^{*}$ & $1.54 \pm 0.18^{*}$ & $1.68 \pm 0.13 *$ \\
\hline $\begin{array}{l}\text { MLob } \\
(\mathrm{mm})\end{array}$ & $0.25 \pm 0.07 *$ & $0.21 \pm 0.05^{*}$ & $0.82 \pm 0.06^{*}$ & $0.88 \pm 0.05^{*}$ & $0.66 \pm 0.07 *$ & $0.88 \pm 0.05 *$ & $0.82 \pm 0.05^{*}$ & $0.88 \pm 0.04 *$ & $0.83 \pm 0.07^{*}$ & $0.89 \pm 0.04 *$ \\
\hline $\begin{array}{l}\text { MWob } \\
(\mathrm{mm})\end{array}$ & $0.25 \pm 0.07 *$ & $0.21 \pm 0.04 *$ & $0.19 \pm 0.02 *$ & $0.20 \pm 0.01^{*}$ & $0.20 \pm 0.02 *$ & $0.20 \pm 0.02 *$ & $0.20 \pm 0.02$ & $0.20 \pm 0.02$ & $0.20 \pm 0.02 *$ & $0.21 \pm 0.01 *$ \\
\hline
\end{tabular}




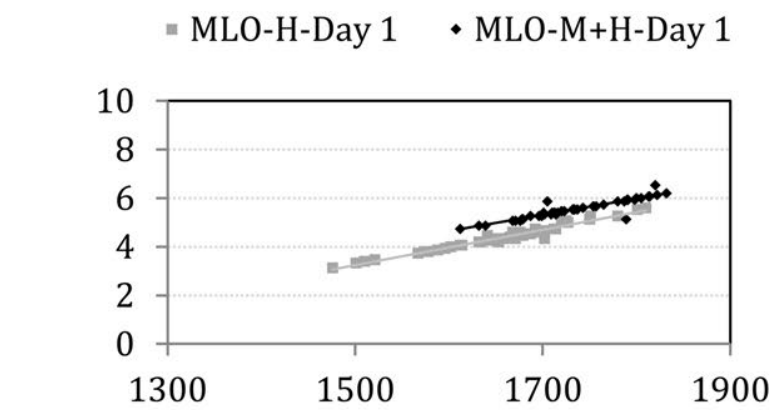

- MLob -H-Day 1 - MLob-M+H-Day 1

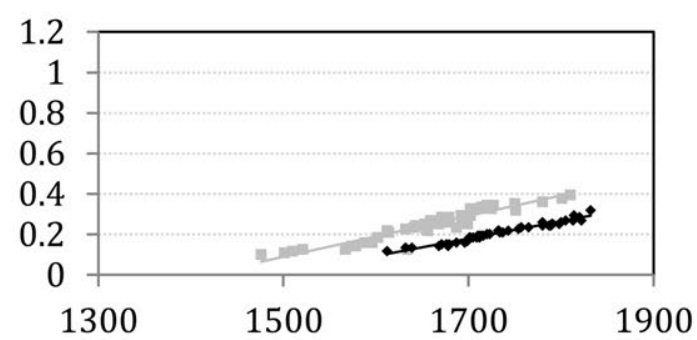

= MLO-H-Day 5 • MLO-M+H-Day 5

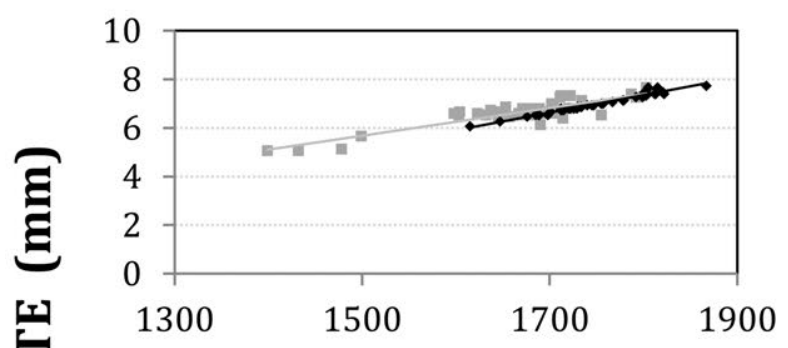

-" MLob-H-Day 5 • MLob-M+H-Day 5
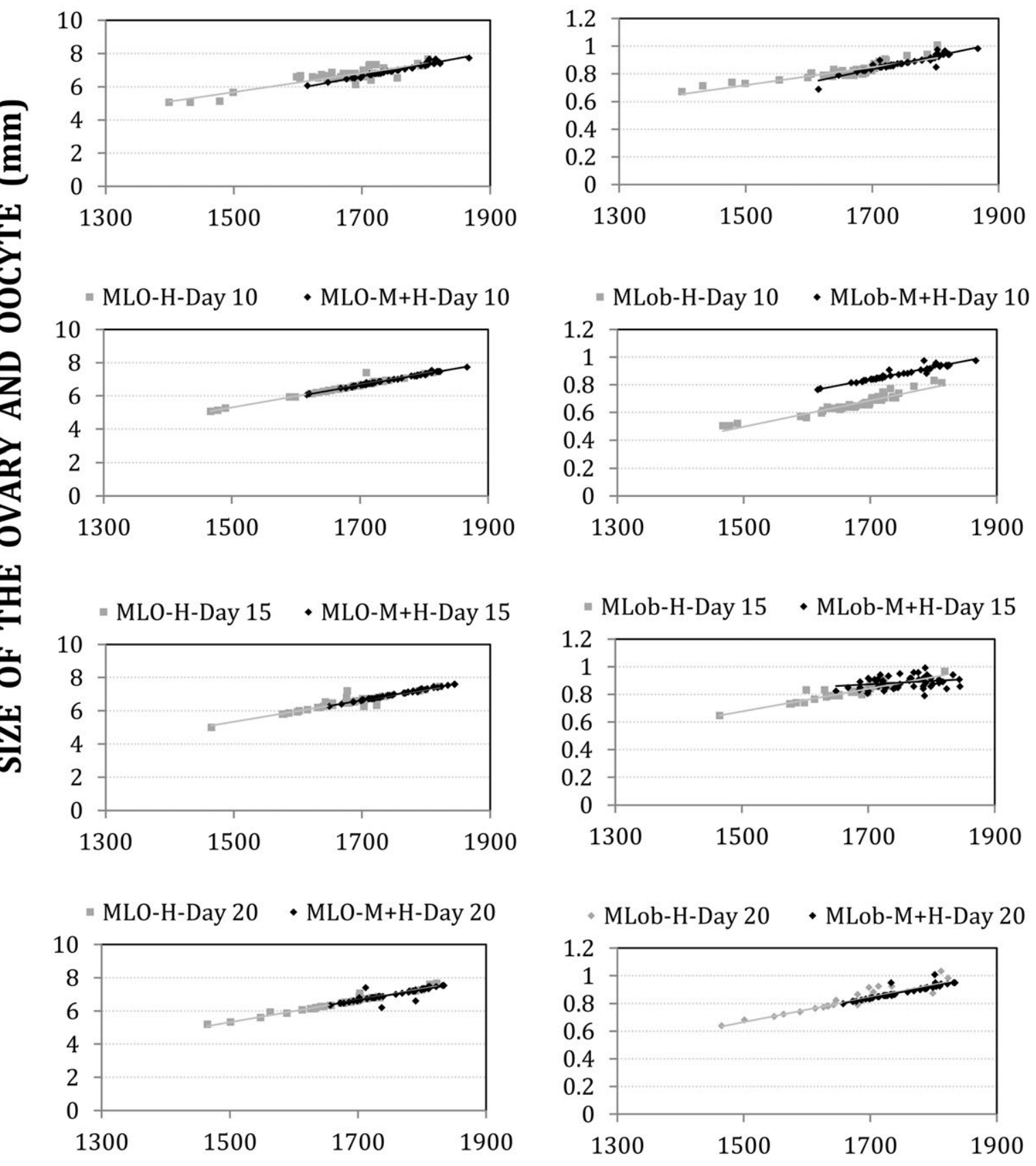

\section{CENTROID SIZE}

Fig. 6. Relationships between the MLO (maximum length of the ovary) and MLob (maximum length of the largest basal oocyte) of the ovaries of females reared on hen feed $(H)$ (grey) and meat meal + hen feed $(M+H)$ (black). Insufficient females were reared on the meat meal (M) diet for a statistical analysis. 
TABLE 3. Correlation coefficient $(r)$ of linear equation between centroid size and female size with the maximum length (MLO), width of the ovary (MWO), the maximum length (MLob) and width of the basal oocyte (MWob) recorded on the three diets $\left({ }^{*} p<\right.$ $0.001)$.

\begin{tabular}{|c|c|c|c|c|c|c|c|c|c|}
\hline \multirow{2}{*}{ Diets } & \multicolumn{5}{|c|}{ Centroid size } & \multicolumn{4}{|c|}{ Female size } \\
\hline & DAY & MLO & MWO & MLob & MWob & MLO & MWO & MLob & MWob \\
\hline \multirow{5}{*}{$\mathrm{H}$} & 1 & $0.98^{*}$ & $0.84 *$ & $0.95^{*}$ & $0.95^{*}$ & $0.82 *$ & $0.82 *$ & $0.80 *$ & $0.80 *$ \\
\hline & 5 & $0.87^{*}$ & $0.80^{*}$ & $0.88^{*}$ & $0.77 *$ & $0.82 *$ & $0.74 *$ & $0.80^{*}$ & $0.75^{*}$ \\
\hline & 10 & $0.98^{*}$ & $0.93^{*}$ & $0.95^{*}$ & $0.82 *$ & $0.83^{*}$ & $0.86^{*}$ & $0.85^{*}$ & $0.80^{*}$ \\
\hline & 15 & $0.93^{*}$ & $0.86^{*}$ & $0.92 *$ & $0.79^{*}$ & $0.76^{*}$ & $0.78^{*}$ & $0.83^{*}$ & $0.74 *$ \\
\hline & 20 & $0.98^{*}$ & $0.92 *$ & $0.92 *$ & $0.89^{*}$ & $0.85^{*}$ & $0.76^{*}$ & $0.75^{*}$ & $0.75^{*}$ \\
\hline \multirow{5}{*}{$\mathrm{M}+\mathrm{H}$} & 1 & $0.92 *$ & $0.84 *$ & $0.98^{*}$ & $0.98^{*}$ & $0.89 *$ & $0.84 *$ & $0.73 *$ & $0.73 *$ \\
\hline & 5 & $0.98^{*}$ & $0.88^{*}$ & $0.93 *$ & $0.88^{*}$ & $0.92 *$ & $0.93^{*}$ & $0.74 *$ & $0.74 *$ \\
\hline & 10 & $0.99 *$ & $0.91^{*}$ & $0.96^{*}$ & $0.88^{*}$ & $0.93^{*}$ & $0.89 *$ & $0.75^{*}$ & $0.72 *$ \\
\hline & 15 & $0.99 *$ & $0.95^{*}$ & $0.98^{*}$ & $0.88^{*}$ & $0.94 *$ & $0.93^{*}$ & $0.79 *$ & $0.75^{*}$ \\
\hline & 20 & $0.88^{*}$ & $0.78^{*}$ & $0.92 *$ & $0.69^{*}$ & $0.82 *$ & $0.89^{*}$ & $0.78^{*}$ & $0.72 *$ \\
\hline M & 1 & $0.99 *$ & $0.96^{*}$ & $0.99 *$ & $0.99 *$ & $0.92 *$ & $0.92 *$ & $0.85^{*}$ & $0.85^{*}$ \\
\hline
\end{tabular}

vival when reared on four different types of pig manure (Cickova et al., 2012).

Other factors, such as adult body size (Livdahl, 1982; Carpenter, 1983; Briegel 1990a; Broadie \& Bradshaw, 1991; Akoh et al., 1992; Bradshaw \& Holzapfel, 1992; Clements, 1992) and the number of ovarioles and size of the ovaries of females (Hawley, 1988; Clements, 1992) are determined by the conditions in which the larvae develop. These can also strongly affect population growth (Blackmore \& Lord, 2000). Numerous studies on mosquitoes have shown a positive relationship between wing size (or other measurements of body size) and fecundity (Livdahl \& Sugihara, 1984; Packer \& Corbet, 1989; Briegel, 1990a, b; Reeves, 1990; Bradshaw \& Holzapfel, 1992; Clements, 1992; Renshaw et al., 1994). Our data show that females with large wings have larger bodies and are more fertile than females with small wings and bodies. This is the case for the largest females with the largest ovaries and basal oocytes that were reared on the hen feed diet, and most markedly on the mixed diet containing hen feed. Both the ovaries and eggs of females reared on the hen feed diet were large five days after emergence, whereas the eggs of those reared on the mixed diet did not fully develop until the fifteenth day. Studies on Muscidae and other insects have shown that a decrease in the quantity and/or quality of the food available to larvae results in the development of small adults (e.g. Black \& Krafsur, 1987; Honek, 1993). Similar results were recorded when the adults of BSF reared on larval media based on a hen feed vs. meat meal diet were compared. The nutritional value of meat meal is mainly based on 50\% protein (animal origin) and 18\% fat (ash content $17.9 \%$ ). In the case of hen feed, however, the values are $14.5 \%$ protein (vegetal origin) and $4 \%$ fat (ash content $13 \%$ ). The quantity ingested by the larvae is so low in the first case that larvae spend more time feeding than when fed on hen feed diets, however, even so the energy resources of the adults are insufficient for normal development and reproduction. For this reason it is very important to analyze the whole life history of insects reared on different diets in order to determine the effects these diets have on the fitness of BSF adults (Blanckenhorn, 2000; Gotthard et al., 2007; Pastor et al., 2011).

Some aspects of the morphology of adult insects, such as wing size, are influenced by both genetic and environmental variables; these variations provide relevant information on many aspects of insect biology, mortality, fertility and sex ratio (Blackmore \& Lord, 2000). In this study, a very high percentage of the larvae reared on the meat meal diet died, and those that survived took longer to complete their larval and pupal development. This is expected because a decrease in the nutritional quality of the food available to larvae is associated with a significant increase in the percentage mortality recorded in the preimaginal stages (Sheppard et al., 1994). According to Roper et al. (1996) the longer larval development of Chrysomya megacephala (Diptera: Calliphoridae) when reared on meat meal may be due to the greater amount of time needed to assimilate the nutrients necessary to achieve the minimum weight for pupation.

The flies reared on the mixed diet (meat meal + hen feed) were better developed in terms of the size of their ovaries and body size than those reared on either the hen feed or meat meal diets, possibly because there was a greater quantity of essential nutrients in the combined diet. However, the greater percentage mortality recorded on the mixed than on the hen feed diet may have been because the larvae spent more time feeding on the meat meal + hen feed diet and therefore had to compete more for the resource.

The variation in wing morphology, body size and fecundity recorded for $H$. illucens reared on different diets could help us improve the artificial rearing of this species. The morphological and biological traits of different insects is affected drastically by the quantity and quality of the food stored during the juvenile stages (Magnarelli \& Anderson, 1979), which could be important in the natural history of the BSF, and for which there 
is little information. For this reason it is important to know the nutritional quality of the different artificial diets and their effect on body mass and/or size of individuals, so that it is possible to maximize the continuous production of eggs necessary for the mass-rearing of this species. However, the effects of other factors such as larval density, adult density and environmental conditions also need to be studied in depth in order to improve massproduction and applied use of the BSF. Our results revealed that the diet given to the larvae could have an important effect on larval developmental time, mortality and ovarian development of this species. Suitable and cost-effective larval media for black soldier flies is one of the bottlenecks that need to be overcome in the next few years.

ACKNOWLEDGEMENTS. This study was funded by a contract between the company Flysoil S.L. and the University of Alicante (FLYSOIL 2-09I), the scholarship sub-programme Torres Quevedo 2010-2012 (Ministry of Innovation and Science 2012) and partially by the projects GRE09-27 (University of Alicante) and GV/2011/039 (Generalitat Valenciana).

\section{REFERENCES}

Aкон J.I., Aigbodion F.I. \& Kumbak D. 1992: Studies on the effect of larval diet, adult body weight, size of blood-meal and age on the fecundity of Culex quinquefasciatus (Diptera: Culicidae). - Insect Sci. Appl. 13: 177-181.

Black W.C. \& Krafsur E.S. 1987: Fecundity and size in the housefly: investigations of some environmental sources and genetic correlates of variation. - Med. Vet. Entomol. 1: 369-382.

Blackmore M.S. \& Lord C.C. 2000: The relationship between size and fecundity in Aedes albopictus. - J. Vector Ecol. 25: 212-217.

BlanCKenhorn W.U. 2000: The evolution of body size: what keeps organisms small? - Q. Rev. Biol. 75: 385-407.

BooKsTEIN F.L. 1991: Morphometrics Tools for Landmark Data. Geometry and Biology. Cambridge University Press, New York, $435 \mathrm{pp}$.

Booth D.C. \& Sheppard D.C. 1984: Oviposition of the black soldier fly, Hermetia illucens (Diptera: Stratiomyidae): eggs, masses, timing and site characteristics. - Environ. Entomol. 13: 21-423.

Bradshaw W.E. \& Holzapfel C.M. 1992: Reproductive consequences of density-dependent size variation in the pitcherplant mosquito, Wyeomyia smithii (Diptera: Culicidae). Ann. Entomol. Soc. Am. 85: 274-281.

Breigel H. 1990a: Fecundity, metabolism, and body size in Anopheles (Diptera: Culicidae), vectors of malaria. - J. Med. Entomol. 27: 839-850.

Breigel H. 1990b: Metabolic relationship between female body size, reserves, and fecundity of Aedes aegypti. - J. Insect Physiol. 36: 165-172.

Broadie K.S. \& Bradshaw W.E. 1991: Mechanisms of interference competition in the western tree-hole mosquito, Aedes sierrensis. - Ecol. Entomol. 16: 145-154.

CARPENTER S.R. 1983: Resource limitation of larval treehole mosquitoes subsisting on beech detritus. - Ecology 64 219-223.

Cickova H., Pastor P., Kozanek M., Martínez-Sánchez A., RoJo S. \& TAKAC P. 2012: Biodegradation of pig manure by the housefly, Musca domestica: A viable ecological strategy for pig manure management. - PLoS ONE 7: e32798. doi:10.1371/journal.pone.0032798.

Clemens A.N. 1992: The Biology of Mosquitoes, Development, Nutrition, and Reproduction. Chapman \& Hall, London, 509 pp.

Diener S., Zurbrugg C. \& Tockner K. 2009: Conversion of organic material by black soldier fly larvae: establishing optimal feeding rates. - Waste Manag. Res. 27: 603-610.

Engelman F. 1984: Reproduction in insects. In Huffaker C.B. \& Rabb R.L. (eds): Ecological Entomology. John Wiley and Sons, New York, 844 pp.

Furman D.P., Young R.D. \& CATTS E.P. 1959: Hermetia illucens (Linnaeus) as a factor in the natural control of Musca domestica (Linnaeus). - J. Econ. Entomol. 52: 917-921.

Gobbi P., Martínez-SÁnchez A. \& Rojo S. 2013: Mass rearing of Hermetia illucens (Diptera: Stratiomyidae): identifying bottlenecks in egg production. - Bull. Entomol. Res (in press).

Gotthard K., Berger D. \& Walters R. 2007: What keeps insects small? Time limitation during oviposition reduces the fecundity benefit of female size in a butterfly. - Am. Nat. 169: 768-779.

Hawley W.A. 1988: The biology of Aedes albopictus. - J. Am. Mosq. Control Assoc. 4: 1-40.

Hem S., Toure S., Sagbla C. \& Legendre M. 2008: Bioconversion of palm kernel meal for aquaculture: Experiences from the forest region (Republic of Guinea). - Afr. J. Biotechnol. 7: 1192-1198.

HoNEK A. 1993: Intraspecific variation in body size and fecundity in insects: a general relationship. — Oikos 66: 483-492.

Jirakanjanakit N., Leemingsawat S., Thongrungkiat S., ApIwathnasorn C., Singhaniyom S., Bellec C. \& Dujardin J.P. 2007: Influence of larval density or food variation on the geometry of the wing of Aedes aegypti (Stegomyia). - Trop. Med. Int. Health. 12: 1354-1360.

LARDÉ G. 1989: Investigation on some factors affecting larval growth in a coffee-pulp bed. - Biol. Wastes 30: 11-19.

Liu Q.L., Tomberlin J.K., BRAdY J.A., SANFord M.R. \& Yu Z.N. 2008: Black soldier fly (Diptera: Stratiomyidae) larvae reduce Escherichia coli in dairy manure. - Environ. Entomol. 37: $1525-1530$.

LivDAHL T.P. 1982: Competition within and between hatching cohorts of a treehole mosquito. - Ecology 63: 1751-1760.

Livdahl T.P. \& Sugihara G. 1984: Non-linear interactions of populations and the importance of estimating per capita rates of change. - J. Anim. Ecol. 53: 573-580.

Magnarelli L.A. \& ANDERson J.F. 1979: Oviposition, fecundity and fertility of the salt marsh deer fly Chrysops fuliginosus (Diptera: Tabanidae). - J. Med. Entomol. 15: 176-179.

Magnarelli L.A., Leprince D.J., Burger J.F. \& Butler J.F. 1982: Oviposition behavior and fecundity in Chrisops cincticornis (Diptera: Tabanidae). - J. Med. Entomo1. 19: 597-600.

Martínez-Sánchez A., Magaña C., Saloña M. \& Rojo S. 2011: First record of Hermetia illucens (Diptera: Stratiomyidae) on human corpses in Iberian Peninsula. - Forensic Sci. Int. 206: 76-78.

Milankov V., Francuski L., LudošKi J., StÅhls G. \& Vujic A. 2010: Genetic structure and phenotypic diversity of two northern populations of Cheilosia aff. longula (Diptera: Syrphidae) has implications for evolution and conservation. Eur. J. Entomol. 107: 305-315.

Morales-Vargas R.E., Ya-Umphana P., Phumala-Morales N., KomalamisraA N. \& Dujardina J.P. 2010: Climate associated size and shape changes in Aedes aegypti (Diptera: Culicidae) 
populations from Thailand. - Infect. Genet. Evol. 10: $580-585$.

Myers H.M., Tomberlin J.K., Lambert B.D. \& David K. 2008: Development of black soldier fly (Diptera: Stratiomyidae) larvae fed dairy manure. - Environ. Entomol. 37: 11-15.

Newton L., Sheppard C., Watson D.W., Burtle G. \& Dove R. 2005a: Using the Black Soldier Fly, Hermetia illucens, as a Value-added Tool for the Management of Swine Manure. Animal and Poultry Waste Management Center, North Carolina State University, Raleigh, NC, 17 pp.

Newton G.L., Sheppard D.C., Watson D.W., Burtle G., Dove C.R., Tomberlin J.K. \& Thelen E.E. 2005b: The black soldier fly, Hermetia illucens, as a manure management/resource recovery tool. In Proc. Symp. on the State of the Science of Animal Manure and Waste Management, San Antonio, TX, USA, January 5-7, 2005. pp. 2-17.

PACKer M.J. \& Corbet P.S. 1989: Size variation and reproductive success of female Aedes punctor (Diptera: Culicidae). Ecol. Entomol. 14: 297-309.

PARRA J.R.P. 1990: Consumo e utilização de alimentos por insetos. In Panizzi A.R. \& Parra J.R.P. (eds): Ecologia Nutricional de Insetos e suas Implicações no Manejo de Pragas. Manole, São Paulo, pp. 9-57.

Pastor B., Iková H., KozÁnek M., Martínez-Sánchez A., Taká P. \& Rojo S. 2011: Effect of the size of the pupae, adult diet, oviposition substrate and adult population density on egg production in Musca domestica (Diptera: Muscidae). — Eur. J. Entomol. 108: 587-596.

Prudhomme J., Gunay F., Rahola N., Ouanaimi F., Guernaou S., Boumezzough A., Bañuls A.L., Sereno D. \& Alten B. 2012: Wing size and shape variation of Phlebotomus papatasi (Diptera: Psychodidae) populations from the south and north slopes of the Atlas Mountains in Morocco. - J. Vector Ecol. 37: $137-47$.

ReEves W.C. 1990: Epidemiology and Control of MosquitoBorne Arboviruses in California, 1943-1987. California Mosquito and Vector Control Association, Sacramento, CA, 508 pp.

Renshaw M., Service M.W. \& Birley M.H. 1994: Size variation and reproductive success in the mosquito Aedes cantans. Med. Vet. Entomol. 8: 179-186.
RoHLF F.J. 1993: Relative warp analysis and an example of its application to mosquito wings. In Marcus L.F., Bello E. \& García-Valdecasas A. (eds): Contribution to Morphometrics. CSIC, Madrid, pp. 131-159.

Rohlf F.J. 2009: Tps Software. State University of New York, Departament of Ecology and Evolution, Stony Brook. http//life.bio.sunysb.edu/morph/.

Roper C., Pignatelli P. \& Partridge L. 1996: Evolutionary responses of Drosophila melanogaster life history to differences in larval density. - J. Evol. Biol. 9: 609-622.

ShePpard D.C. \& Newton G.L. 2000: Valuable byproducts of a manure management system using the black soldier fly. A literature review with some current results. In: Proceedings of the 8th International Symposium of Animal, Agricultural and Food Processing Wastes. American Society of Agricultural Engineers, St. Joseph, MI, pp. 35-39.

Sheppard D.C., Newton G.L. \& Thompson S.A. 1994: A value added manure management system using the black soldier fly. - Bioresource Tech. 50: 275-279.

Sheppard D.C., Tomberlin J.K., Joyce J., Kiser B.C. \& Sumner S.M. 2002: Rearing methods for the black soldier fly (Diptera: Stratiomyidae). - J. Med. Entomol. 39: 695-698.

St-Hilaire S., Cranfill K., McGuire M.A., Mosley E.E., TomBerlin J.K., Newton L., Sealey W.C., Sheppard D.C. \& IRVING S. 2007: Fish offal recycling by the black soldier fly produces a foodstuff high in omega-3 fatty acids. $-J$. World Aquacult. Soc. 38: 309-313.

Soto I.M., Carreira V.P., Soto E.M. \& Hasson E. 2008: Wing morphology and fluctuating asymmetry depend on the host plant in cactophilic Drosophila. - J. Evol. Biol. 21: 598-609.

Tomberlin J.K., Sheppard D.C. \& Joyce J.A. 2002: A comparison of selected life history traits of the black soldier fly (Diptera: Stratiomyidae) when reared on three diets. - Ann. Entomol. Soc. Am. 95: 379-387.

Zelditch M.L., Swiderski D.L., Sheets H.D. \& FinK W.L. 2004: Geometric Morphometrics for Biologists: A Primer. Elsevier, London, $443 \mathrm{pp}$.

Zhang J., Huang L., He J., Tomberlin J.K., Lei C. \& Yu Z. 2010: An artificial light source influences mating and oviposition of black soldier flies (Diptera: Stratiomyidae). $-J$. Insect Sci. 10: 1536-2442.

Received October 1, 2012; revised and accepted January 11, 2013 